\title{
Genetic Mechanisms Underlying Evolution in Crinum
}

\author{
S. N. Raina \\ Cytogenetics Laboratory, Department of Botany, \\ University of Jodhpur, Jodhpur-342001, India
}

Received March 5, 1977

Crinum Linn. of family Amaryllidaceae is a popular ornamental of the world. It contains about 148 species (Traub 1962). The genus was studied from a representative collection of 34 taxa (18 species and 16 cultivars). The methods followed have been detailed earlier (Khoshoo and Raina 1968).

\section{Observations}

An analysis of karyotypic variation, meiosis, pollen mitosis and mitotic mosaicism in 34 taxa has been summarised in Table 1, 2, 3.

Twenty eight taxa (16 species plus 12 cultivars) were found to be diploid with $2 n=22$, which in most cases resolved into more or less 11 pairs. A basic karyotype of one long, about 6 medium and 4 short sized pairs is recognizable (See Raina and Khoshoo 1971a). A small but consistent difference in the size of the two members of the longest pair has been noted in most of the taxa. The six medium sized pairs have their centromeres located from submedian to subterminal position. One of the pairs in this category of chromosomes is always with a secondary constriction located in the longer arms. Various taxa may differ in the exact position of the secondary constriction (See Raina and Khoshoo 1971a). In thirteen taxa the nucleolar chromosomes occur in a heterozygous state. Sometimes a non-nucleolar pair among medium sized chromosomes may also be heteromorphic. The four short pairs have centromeres generally in submedian position, rarely it may be median. One or two pairs may be heteromorphic in some taxa. The basic karyotype of 1 long, 6 medium and 4 short chromosomes is recognizable in all the three triploid taxa, which is represented three times. The karyotype in two taxa of tetraploids resolve into 11 groups, which fall in the usual three size classes. Only Cv. 46 is hexaploid with $2 n=67$ and $2 n=66$. The latter could be resolved in 11 groups of 6 chromosomes each. The eleven groups conform to the usual size pattern (Raina and Khoshoo 1971a).

How far outer karyotypic stability in size and morphology of chromosomes indicates inner homology of chromosomes, can be clarified by an intimate study of meiosis.

C. latifolium is a diploid $(2 \mathrm{n}=22)$. A study of 225 cells at metaphase I revealed a variety of configurations (Table 2; Khoshoo and Raina 1968). Anaphase I was characterised by normal distribution of chromosomes and 1-3 bridge-fragment configurations.

Mitotic mosaicism in C. augustum is summarised in Table 3. About 52 per cent 
Table 1. Karyomorphology and chromosome number in Crinum species and cultivars

\begin{tabular}{|c|c|c|}
\hline Taxon & Karyotypic formula* & $2 n$ \\
\hline \multicolumn{3}{|l|}{ Species } \\
\hline amoenum & $16 \mathrm{~L}+2 \mathrm{Ln}+4 \mathrm{~J}$ & 22 \\
\hline asiaticum & $18 \mathrm{~L}+2 \mathrm{Jn}+2 \mathrm{~J}$ & 22 \\
\hline americanum & $17 \mathbf{L}+2 \mathbf{L n}+3 \mathbf{J}$ & 22 \\
\hline careyanum & $14 \mathrm{~L}+2 \mathrm{Ln}+6 \mathrm{~J}$ & 22 \\
\hline campanulatum & $16 \mathrm{~L}+2 \mathrm{Ln}+4 \mathrm{~J}$ & 22 \\
\hline defixum & $15 \mathrm{~L}+2 \mathrm{Ln}+3 \mathrm{~V}+2 \mathrm{~J}$ & 22 \\
\hline erubescens & $14 \mathrm{~L}+2 \mathrm{Ln}+2 \mathrm{~V}+4 \mathrm{~J}$ & 22 \\
\hline fimbriatulum & $18 \mathrm{~L}+2 \mathrm{Ln}+2 \mathrm{~J}$ & 22 \\
\hline kunthianum & $16 \mathrm{~L}+2 \mathrm{Ln}+4 \mathrm{~J}$ & 22 \\
\hline$k i r k i i$ & $11 \mathrm{~L}+2 \mathrm{Ln}+4 \mathrm{~V}+5 \mathrm{~J}$ & 22 \\
\hline lineare & $18 \mathrm{~L}+2 \mathrm{Ln}+2 \mathrm{~J}$ & 22 \\
\hline latifolium & $18 \mathrm{~L}+2 \mathrm{Ln}+2 \mathrm{~J}$ & 22 \\
\hline moorei & $16 L+2 L n+4 J$ & 22 \\
\hline powellii & $20 \mathrm{~L}+2 \mathrm{Ln}$ & 22 \\
\hline scabrum & $17 \mathbf{L}+2 \mathbf{L n}+3 \mathrm{~J}$ & 22 \\
\hline zeylanicum & $14 \mathrm{~L}+2 \mathrm{Ln}+6 \mathrm{~J}$ & 22 \\
\hline augustum & $26 \mathrm{~L}+1 \mathrm{Ln}+6 \mathrm{~J}$ & 33 \\
\hline polyphyllum & $34 \mathrm{~L}+2 \mathrm{Ln}+8 \mathrm{~J}$ & 44 \\
\hline \multicolumn{3}{|l|}{ Cultivars } \\
\hline Cv. 2. & $12 \mathrm{~L}+2 \mathrm{Ln}+2 \mathrm{~V}+6 \mathrm{~J}$ & 22 \\
\hline Cv. 7. & $14 \mathrm{~L}+2 \mathrm{Jn}+6 \mathrm{~J}$ & 22 \\
\hline Cv. 8. & $18 \mathrm{~L}+2 \mathrm{Ln}+2 \mathrm{~J}$ & 22 \\
\hline Cv. 11. & $14 \mathrm{~L}+2 \mathrm{Ln}+6 \mathrm{~J}$ & 22 \\
\hline Cv. 15 . & $14 \mathrm{~L}+2 \mathrm{Ln}+2 \mathrm{~V}+4 \mathrm{~J}$ & 22 \\
\hline Cv. 20. & $18 \mathrm{~L}+2 \mathrm{Ln}+2 \mathrm{~V}$ & 22 \\
\hline Cv. 21. & $12 \mathrm{~L}+2 \mathrm{Ln}+2 \mathrm{~V}+6 \mathrm{~J}$ & 22 \\
\hline Cv. 26. & $14 \mathrm{~L}+2 \mathrm{Ln}+6 \mathrm{~J}$ & 22 \\
\hline Cv. 33. & $25 \mathrm{~L}+2 \mathrm{Ln}+6 \mathrm{~J}$ & 33 \\
\hline Cv. 36. & $19 \mathrm{~L}+2 \mathrm{Ln}+12 \mathrm{~J}$ & 33 \\
\hline Cv. 38 . & $11 L+2 L n+1 V+8 J$ & 22 \\
\hline Cv. 46. & $42 L+6 L n+6 V+12 J$ & 66 \\
\hline Cv. 49. & $18 \mathrm{~L}+2 \mathrm{Ln}+2 \mathrm{~J}$ & 22 \\
\hline Cv. 50. & $16 L+2 L n+4 J$ & 22 \\
\hline Cv. 51. & $12 \mathrm{~L}+2 \mathrm{Ln}+2 \mathrm{~V}+6 \mathrm{~J}$ & 22 \\
\hline Cv. 52. & $31 \mathrm{~L}+1 \mathrm{Ln}+4 \mathrm{~V}+8 \mathrm{~J}$ & 44 \\
\hline
\end{tabular}

* $\quad \mathrm{V}=$ Metacentric, $\mathrm{L}=$ Submetacentric, $\mathrm{J}=$ =Subtelocentric, $\mathrm{I}=$ Telocentric, $\mathrm{n}=$ Nucleolar chromosome, See Khoshoo and Raina 1968.

cells contain 33 chromosomes which as usual resolve into 11 triplets. In the next $45.5 \%$ cells instead of the regular complement of 33 chromosomes, there are found 32 plus a small telocentric chromosome. The telocentric chromosome corresponds to the short arm of the third small submedian chromosome of the last triplet (Raina and Khoshoo 1971b). Four deviant cells $(2.5 \%)$ were found to have $33+\mathrm{Te}$, $37+\mathrm{Te}, 34$ and 32 complement of chromosomes.

In the above material cells with complement $(2 n=33)$ only, are selected in the germline. As is evident from Table 2, on average there are $0.46 \mathrm{III}+10.51 \mathrm{II}$ 
Table 2. Male meiosis in C. latifolium and C. augustum

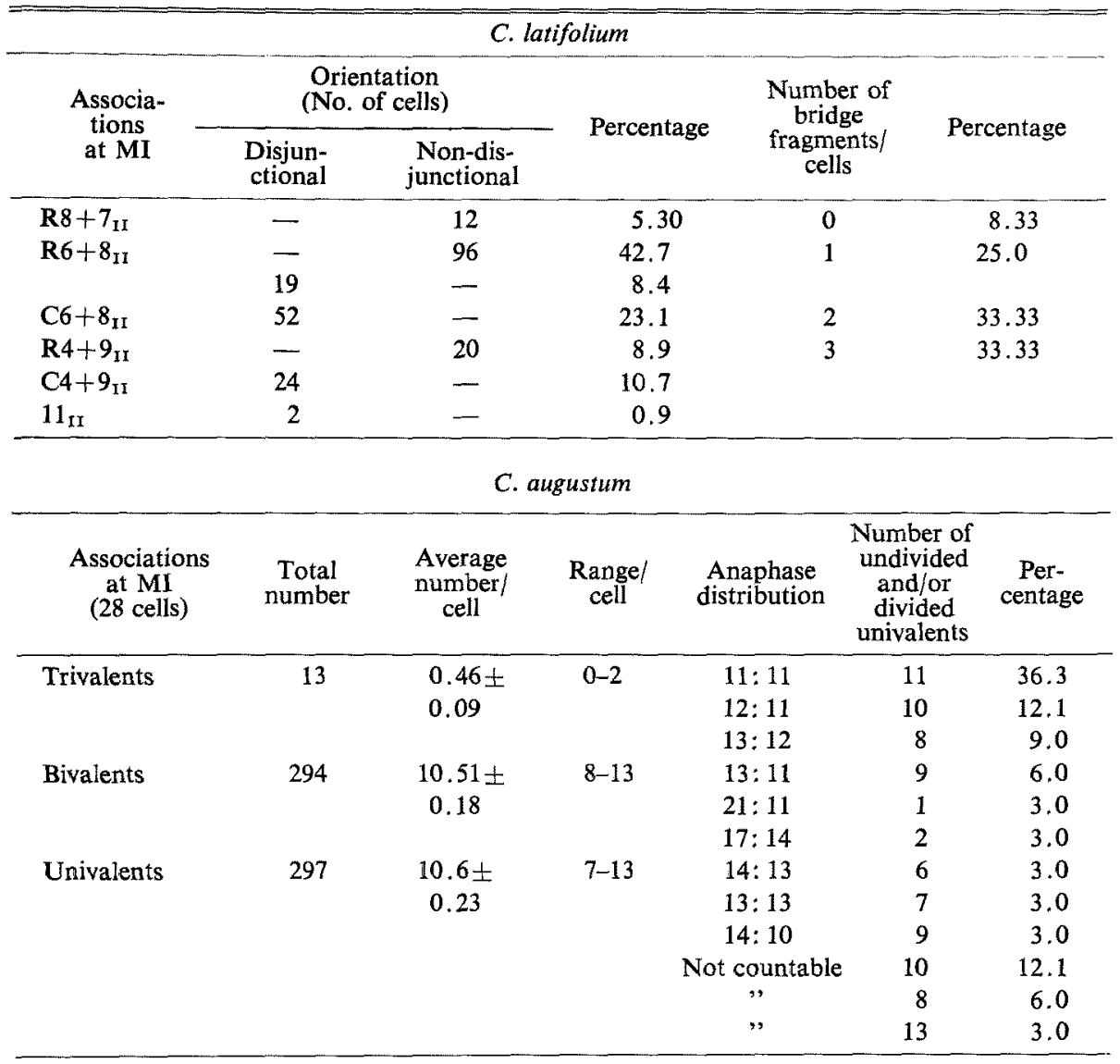

and 10.6 I per cell. Anaphase I was characterised by unequal distribution of chromosomes to poles with univalents dividing precociously in the middle (Table 2; Raina and Khoshoo 1971c). The pollen grains scored for pollen mitosis, had different chromosome numbers (Table 3). In addition micropollen grains with 1 chromosome were also found.

The present data together with those published by earlier authors show that the somatic number ranges from $2 n=22,24,33,44,66$ to about 88 . There is an overwhelming evidence that the basic number of the genus is $x=11$ (Raina and Khoshoo 1971a). The number $2 \mathrm{n}=24$ found in one cytotype of $C$. ornatum is definitely derived from $x=11$ (Jones and Smith 1967). The present studies has revealed several interesting points which together with earlier studies, will help in understanding the factors underlying evolution of the species. These may be now discussed. 
Discussion

Chromosomal repatterning

The work of Jones and Smith (1967) and the present author has clearly shown an underlying uniformity of the basic karyotype in the genus at diploid and polyploid levels. The basic karyotype of 11 chromosomes is composed of 1 long median-

Table 3. Pollen grain mitosis and mitotic mosaicism in C. augustum

\begin{tabular}{|c|c|c|c|c|c|c|}
\hline \multicolumn{2}{|c|}{ Pollen grain mitosis } & \multicolumn{5}{|c|}{ Chromosome variation in root tips $(\mathrm{Te}=$ telocentric) } \\
\hline \multirow{2}{*}{$\begin{array}{l}\text { Chromosome } \\
\text { number (n) }\end{array}$} & \multirow{2}{*}{$\begin{array}{l}\text { Number } \\
\text { of cells }\end{array}$} & \multirow{2}{*}{$\begin{array}{l}\text { Chromo- } \\
\text { some } \\
\text { number } \\
(2 n)\end{array}$} & \multicolumn{2}{|c|}{ Number of cells } & \multirow{2}{*}{$\begin{array}{c}\text { Total } \\
\text { number }\end{array}$} & \multirow{2}{*}{ Percentage } \\
\hline & & & $\begin{array}{l}\text { Primary } \\
\text { roots }\end{array}$ & $\begin{array}{l}\text { Secondary } \\
\text { roots }\end{array}$ & & \\
\hline $\begin{array}{c}1 \\
\text { (Micropollen) }\end{array}$ & 4 & 33 & $\begin{array}{c}40 \\
(49.39 \%)\end{array}$ & $\begin{array}{c}42 \\
(54.55 \%)\end{array}$ & 82 & 51.898 \\
\hline 11 & 2 & $32+\mathrm{Te}$ & $\begin{array}{c}38 \\
(46.92 \%)\end{array}$ & $\begin{array}{c}34 \\
(44.16 \%)\end{array}$ & 72 & 45.569 \\
\hline 13 & 1 & $33+\mathrm{Te}$ & - & $\begin{array}{c}1 \\
(1.29 \%)\end{array}$ & 1 & 0.632 \\
\hline 14 & 3 & & & & & \\
\hline 15 & 2 & $37+\mathrm{Te}$ & $\begin{array}{c}1 \\
(1.23 \%)\end{array}$ & - & 1 & 0.632 \\
\hline $17+$ Ring & 1 & 34 & $\begin{array}{c}1 \\
(1.23 \%)\end{array}$ & - & 1 & 0.632 \\
\hline 18 & 2 & 32 & 1 & - & 1 & 0.632 \\
\hline 23 & 1 & & $(1.23 \%)$ & & & \\
\hline
\end{tabular}

submedian, 6 medium median-subterminal and 4 short median-submedian chromosomes. One of the medium chromosomes possesses a secondary constriction. The different taxa at any one ploidy level do not appear to differ significantly in chromosome size, but differ in exact position of centromere in the three size classes, with the result the number of $\mathrm{V}, \mathrm{L}$ and $\mathrm{J}$ chromosomes while constant for a taxon, varies between taxa. Similarly the exact position of secondary constriction is also not constant (Raina and Khoshoo 1971a). In addition to such repatterning within taxa, because, in many cases, while the basic karyotype is constant, the diploid and polyploid complements do not resolve into 11 identical sets. This may have been brought about by hybridization between taxa with different karyotypes or by segmental interchanges. Such heteromorphicity is almost a constant feature of the long pair and also involves upto 3 other pairs from medium and small class, often including the nucleolar pair as well. The meiotic studies in two diploids reveal that $C$. asiaticum (karyotypically a homozygote), possess 11 bivalents, while C. latifolium (heteromorphic for 3 pairs in addition to the long pair), possess rings or chains of 4, 6 and 8 chromosomes and also upto 3 bridge-fragments (Khoshoo and Raina 1968). The long pair forms a heteromorphic bivalent. A comparison of the 2 homologues of this pair shows that they differ in the length of the short arm which could have been brought about by a terminal deletion. The above findings show that although there is a phenotypic stability of chromosomes, yet they contain a measure of structural differentiation which can only be brought to 
light through meiotic studies.

Yet another type of repatterning is found in $3 \mathrm{x}$ C. augustum which is a chromosomal mosaic (Table 3). From a critical comparison of the two karyotypes, it can be inferred that one of the smallest chromosomes has undergone misdivision very early in the ontogeny, resulting in a centric small arm and acentric long arm. The former being centric, functions normally (Raina and Khoshoo 1971b). A meiotic study reveals that in the germ line only full complement containing 33 chromosomes is selected.

From the above, it is clear that mechanism responsible for detectable and undetectable chromosomal repatterning are, unequal segmental interchanges, deletions, peri- and paracentric inversions and misdivision.

\section{Hybridization}

Crinums are known to hybridize freely (Bailey 1963). These are cross pollinated and a large number of interspecific hybrids have been produced. Hannibal (1962, 1964) has surveyed the literature on hybridization in the genus and not only some well known species like $C$. powellii $(C$. capense $\times C$. moorei) but also a large number of cultivars represent interspecific hybrids and hybrid segregates.

All hybrids except one, $C$. 'Luther Burbank' (C. macowanii $\times C$. yemense, Hannibal 1964), are sterile and in fact most of the so-called sterile species and cultivars may be interspecific hybrids. This evidently indicates a high degree of genetic differentiation between species.

From the foregoing survey it looks that hybridization has been involved in the origin of garden cultivars and also some taxa in nature. Karyotypic heteromorphicity involving number and structure of nucleolar and non-nucleolar chromosomes is also indicative of involvement of hybridization (Raina and Khoshoo 1971a).

\section{Polyploidy}

The present data together with earlier data, indicates that about $21.3 \%$ taxa in Crinum are polyploid and polyploidy is both at intra and interspecific levels ranging from $3 \mathrm{x}$ to about $8 \mathrm{x}$ level. The basic karyotype is multiplied in the polyploids and ordinarily it does not shed much light on the nature of ploidy. However, a detailed comparison of the marker chromosomes like the long and the nucleolar pairs reveals a good deal of heteromorphicity in these chromosomes. This could have been brought about by hybridization between different taxa.

The only polyploid species studied for its meiosis is the $3 \mathrm{x} C$. augustum (Raina and Khoshoo 1971c; Table 2). Usually there are 11 bivalents and 11 univalents at metaphase I, which may indicate its alloploid nature and is corroborated by its karyotypic analysis which also is indicative of hybridity having been involved in its origin.

\section{Summary}

The genus Crinum is relatively stable cytologically, about $79 \%$ taxa are diploid and $21 \%$ are polyploid ranging from $3 \mathrm{x}$ to about $8 \mathrm{x}$. The diploids are essentially karyotypically stable and while retaining a basic karyotype, the various taxa differ 
in the extent of heteromorphicity in the marker chromosomes like the long and nucleolar pairs. Hybridization is common and it may have been responsible for part of the karyotypic heteromorphicity both at $2 \mathrm{x}$ and polyploid levels. The karyotypic analysis of polyploids and the meiotic study of one triploid taxon indicate allo- or segmental alloploidy may be rather common. In view of the sterility of hybrids there appears a strong genetic differentiation between the taxa.

Much of the evolution in this genus, in nature and in garden, appears to have taken place at diploid level through unequal interchanges, para- and pericentric inversions, deletions, misdivision, hybridization and above all by gene mutation. Polyploidy has not played a dominant role.

\section{Acknowledgments}

It gives me great pleasure to acknowledge my gratitude to Dr. T. N. Khoshoo, Director, National Botanic Gardens, Lucknow for guidance throughout the course of this work.

\section{References}

Bailey, L. H. 1963. The Standard Cyclopedia of Horticulture. Macmillan Company, New York. Hannibal, L. S. 1962. Notes on Crinum breeding. PI. Life 18: 88-92.

- 1964. Interrelationships of some Garden Crinums. Pl. Life 20: 69-72.

Jones, K. and Smith, J. B. 1967. Chromosome evolution in genus Crinum. Caryologia 20: $163-179$.

Khoshoo, T. N. and Raina, S. N. 1968. Cytogenetics of tropical bulbous ornamentals I. Heterozygosity in Crinum latifolium. Cytologia 33: 209-219.

Raina, S. N. and Khoshoo, T. N. 1971a. Cytogenetics of tropical bulbous ornamentals II. Variation in mitotic complement in Crinum. The Nucleus 14: 23-39.

- 1971b. Cytogenetics of tropical bulbous ornamentals III. Mitotic mosaicism in 3x Crinum augustum. Theo. Appl. Genet. 41: 375-378.

- 1971c. Cytogenetics of tropical bulbous ornamentals IV. Nature of triploidy in Crinum augustum. Cytologia 36: 595-603.

Traub, H. P. 1962. Classification of the Amaryllidaceae. Pl. Life 18: 50-54. 